\title{
Comunicação privada na internet: da invenção do particular na Idade Média à hiperexposição na rede
}

\author{
Alex Primo \\ Doutor; Universidade Federal do Rio Grande do Sul \\ aprimo@ufrgs.br

\section{Ludmila Lupinacci} \\ Mestranda; Universidade Federal do Rio Grande do Sul \\ ludmila.lupinacci@gmail.com
}

\section{Vanessa Valiati}

Doutoranda; Universidade Federal do Rio Grande do Sul vanessa.valiati@gmail.com

\section{Laura Barros}

Mestranda; Universidade Federal do Rio Grande do Sul laurabarros5@gmail.com

\section{Resumo}

Este artigo discute a questão do privado em conversações online. É apresentada uma breve arqueologia da vida privada e uma discussão sobre a interação interpessoal e grupal em serviços de comunicação digital. A partir da reflexão sobre o borramento das esferas pública e privada na contemporaneidade, são apresentados os protocolos de uso de serviços de sociabilidade online que visam orientar comportamentos e evitar problemas quanto à circulação de mensagens privadas. Finalmente, debate-se a quebra desses protocolos de uso, quando há o vazamento de conteúdos íntimos, que passam a ser (intencionalmente ou não) circulados publicamente.

\section{Palavras-chave}

Privado. Privacidade. Público. Intimidade. Relacionamentos online. Amizade. 


\section{Introdução}

Na história da internet comercial, os serviços de mensagens privadas (como e-mail, BBS, IRC e ICQ) foram os primeiros a se popularizar. Apesar do e-mail seguir presente em nosso dia-a-dia, sua decadência tem sido anunciada com alguma frequência. Qualman (2009) argumenta que os jovens se desinteressaram pelo velho correio eletrônico, preferindo a comunicação continuada através de mídias sociais. Uma pesquisa do Pew Research Center (LENHART et al., 2008) já apontava o e-mail como o serviço eletrônico menos usado por adolescentes.

Por outro lado, a compra do WhatsApp pelo Facebook por 19 milhões de dólares, em fevereiro de 2014, ratificou a centralidade da comunicação privada na internet em nosso tempo. Mais do que isso, confirmou como nossas interações particulares se tornaram cobiçadas por empresas que buscam delas extrair alta lucratividade. Com esta disputa, a troca de mensagens interpessoais e grupais sofreu transformações importantes, especialmente devido à ascensão de aplicativos para smartphones, que adicionaram novas funcionalidades, diminuíram o custo de envio, ampliaram as características hipermidiáticas e o limite do tamanho da mensagem.

No âmbito dos estudos de cibercultura, muito já se discutiu sobre como a Web desafia a mídia de massa e sobre a potência de blogueiros e vlogueiros que podem atingir milhões de pessoas com baixíssimo investimento. Por outro lado, o triunfo do WhatsApp e de outros serviços de conversação interpessoal e grupal cada vez mais demandam atenção. Mesmo que essa forma privada de comunicação online seja frequentemente discutida na mídia, ela tem sido pouco estudada na academia. Na verdade, existe uma grande quantidade de trabalhos que tratam de privacidade, mas que enfocam questões de segurança de dados. Este artigo, por outro lado, busca colocar em debate os vários modos da comunicação particular através de uma breve arqueologia da emergência da vida privada e de uma discussão sobre a interação interpessoal e grupal online. A partir disso, discute-se os protocolos de conversação online e a violação e vazamento de mensagens privadas.

\section{Vida privada: uma invenção}

Antes de discutir-se a troca de mensagens na internet é prudente lembrar que a vida privada não é algo próprio da vida humana, como se estivesse presente em nossa existência desde sempre. Trata-se de uma construção, de uma invenção (termo adotado na coleção de 
livros sobre o tema organizada por Philippe Ariès e Georges Duby, (1991)). Até a Idade Média não havia nada de privado na vida cotidiana. "A comunidade que enquadra e limita o indivíduo - comunidade rural, a cidadezinha ou o bairro - constitui um meio familiar em que todo mundo se conhece e se vigia..." (Ariès, 1991, p. 7-8). A rigor, até então ainda não se falava no "privado", mas sim do "particular": tudo aquilo não relacionado com cargos ou que escapasse ao controle do Estado. Conforme define Ariès, (1991) trata-se de um espaçotempo sem relação com a coisa pública. Se até então a solidão igualava-se ao tédio, a partir da Idade Média ela vai ser reconhecida como um refúgio.

Para Ariès (1991), a intimidade individual foi uma conquista que se deu na Europa a partir dos séculos XVI e XVII, à medida que o Estado e a comunidade deixaram de controlar todos os espaços sociais. Mas é apenas no século XIX que o homem buscará preservar-se do olhar alheio, escolher seu estilo de vida e encontrar acolhimento na família. Nesse percurso, Ariès (1991) encontra os seguintes indícios da progressiva privatização no período:

a) o aparecimento de uma "literatura de civilidade", sob a forma de manuais de comportamento, hospitalidade e de conversação;

b) a escrita de diários íntimos (com forma de autoconhecimento) e cartas entre amigos e amantes;

c) a descoberta do prazer de estar sozinho;

d) a escolha deliberada de amigos ${ }^{1}$;

e) a transformação da casa, com espaços menores, especializados (nursery², a sala de estar) e íntimos (o gabinete).

Para Goulemot (1991, p. 372), com a nova organização dos espaços particulares, "A casa se opõe então à organização do espaço urbano (praças, logradouros públicos), que tende a colocar sob o olhar da autoridade e da comunidade toda uma parte das atividades do indivíduo que se tornou sujeito."

A primeira fase do processo de privatização, segundo Ariès (1991, p. 14), foi a conquista da intimidade individual: "Os espaços sociais que a conquista do Estado e os recuos da sociabilidade comunitária deixaram livres vão ceder lugar ao indivíduo para se instalar no isolamento, na sombra". Na fase seguinte ocorre a organização de grupos de convivialidade. Tratam-se de associações de conversação, de leitura em voz alta, de debates. Para

\footnotetext{
${ }^{1}$ Aymard (1991) observa que a amizade passa a constituir-se como um espaço de liberdade, pois o amigo é escolhido e não imposto pela tradição, pela família, pelo trabalho.

${ }^{2}$ Quarto dedicado às crianças da casa.
} 
Chartier (1991), esses grupos — mais amplos que a família, mais restritos que a comunidade - são uma forma de fuga tanto da multidão quanto da solidão. No século XVIII, alguns desses grupos se institucionalizam em clubes, sociedades de pensamento e academias. Ariès (1991) observa que com esse movimento tais grupos perdem sua informalidade e espontaneidade. Por outro lado, nasce ali o que Habermas (2003) vai chamar de esfera pública, quando indivíduos particulares passam a fazer uso público da razão. Portanto, conforme compreensão de Chartier (1991), a esfera pública fundamenta-se na esfera privada. Na mesma direção, Goodman (1992) critica possíveis interpretações de uma separação radical entre público e privado. Para ela, a vida privada é constitutiva da esfera pública habermasiana.

Já na terceira fase da construção da vida privada, conforme Ariès (1991, p. 15), a família transmuta-se de uma unidade econômica e de um polo de controle das ações de cada membro para um "lugar de refúgio onde se escapa dos olhares de fora, lugar de afetividade onde se estabelecem relações de sentimento entre o casal e os filhos, lugar de atenção à infância". Enfim, o que Ariès (1991) observa é a passagem da sociabilidade anônima (na rua, no pátio, na comunidade), quando o privado e o público se confundiam, para uma sociabilidade restrita.

Analisando a exposição de Ariès, Chartier (1991) encontra uma contraditória relação entre civilidade e intimidade. Enquanto a primeira trata das normas que passam a regrar a existência coletiva (nos salões, por exemplo), a intimidade consiste da busca por espaços solitários. Em outras palavras, a civilidade foca a separação dos corpos e o controle dos afetos, enquanto a intimidade visa as aproximações afetivas de amigos, familiares, amantes e companheiros de fé. Como se verá adiante, na internet a separação entre essas duas esferas vai sendo borrada, o que traz repercussões signitificativas à comunicação interpessoal online.

Ao empreender uma arqueologia do íntimo, Ranum (1991) vai encontrar uma série de espaços e objetos ligados ao conhecimento de si e aos relacionamentos amistosos e amorosos: os pequenos jardins privados, o escritório; os objetos-relíquia, que contribuem para a lembrança de amores e amizades; autorretratos, cartas de amor e miniaturas (pequenos retratos pintados, frequentemente usados em colares). 0 autor comenta que a troca de retratos, presentes, roupas e livros entre amigos demonstra "a intensidade crescente da própria amizade" (p. 258). É possível notar como tais objetos funcionam como lembranças materializadas, como os relacionamentos mais próximos passam a ganhar importância no perí- 
odo, e como a construção de fortes laços de amizade (e os presentes e imagens trocadas) revelam a progressiva autonomia dos sujeitos. Mais tarde, mostraremos como presentes virtuais (como fotos íntimas), que deveriam ser mantidas na esfera privada, acabam sendo amplamente circuladas e até debatidas. Contudo, como se problematizará, nem sempre tal vazamento é fruto de invasão criminosa de um computador pessoal.

Mas por que tamanho retrospecto sobre a emergência da privacidade? Primeiramente, é preciso saber de onde se vem, evitando-se assim a ilusão de que tudo está sendo inventado agora em virtude dos avanços tecnológicos. 0 inverso é também um grave equívoco: imaginar que aquilo que vivemos hoje é mera repetição do que outrora existiu. Tampouco trata-se de uma evolução linear. Ora, a história não é simples justaposição de fatos, sendo o anterior causa da atual consequência. 0 percurso histórico não é mero avanço previsível. Ele é repleto de rupturas, surpresas, retrocessos, reinvenções e revoluções ocasionais.

O conceito de remediação (BOLTER; GRUSIN, 2000) é aqui útil, pois trata de como novos meios de comunicação herdam características de meios anteriores. Além disso, novos meios podem remodelar os anteriores e inclusive transformar meios posteriores. Por outro lado, não se pode supor que trata-se apenas da digitalização de meios e práticas anteriores. Por exemplo, blogs não são simplesmente diários íntimos digitais (PRIMO, 2008). Conforme destacam Bolter e Grusin (2000, p. 19, tradução nossa),

[...] novos meios digitais não são agentes externos que vêm abalar uma cultura desprevenida. Eles emergem em contextos culturais, e eles remodelam outras mídias, que estão inseridas nos mesmos ou similares contextos. $^{3}$

Obviamente, a cultura e os relacionamentos de hoje são por demais diferentes daqueles da Idade Média. No entanto, cabe observar-se como são descritos e praticados os modos de interação (o que é ou não apropriado, por exemplo) na internet; como e quando se protege os espaços reservados e/ou se compartilha abertamente questões privadas. Através do contraste das práticas de outras eras com a forma como a intimidade e a privacidade vêm sendo atualizadas é possível interpretar como a subjetividade e a sociabilidade são negociadas em nosso tempo. Enquanto é um equívoco buscar traçar uma evolução sequencial dos comportamentos, também seria tolo desprezar o passado.

Se a história seguisse um caminho linear, provavelmente hoje tudo o que é particular estaria confinado em herméticas câmaras de proteção. No entanto, Sibilia (2008) identifica

\footnotetext{
${ }^{3}$ No original, "New digital media are not external agents that come to disrupt an unsuspecting culture. They emerge from
} within cultural contexts, and they refashion other media, which are embedded in the same or similar contexts." 
na contemporaneidade o que chama de "imperativo da visibilidade". Conforme a lógica da sociedade do espetáculo, tudo aquilo que não é exposto e não entra em um campo de visibilidade, por não ser visto, corre o risco de não existir. Tal afirmativa faz sentido nas interações na internet. Na ausência do corpo, a presença de alguém só é percebida através de suas manifestações. Mais do que um problema tecnológico, Sibilia (2008) apresenta como uma performance exibicionista se faz necessária em uma cultura do espetáculo e da visibilidade. Evidentemente, não há como imaginar como seria a idade média com a internet. Da mesma forma, seria um grave erro sociológico supor que a condição dos relacionamentos atuais são impostos pela tecnologia digital. É apenas através da observação da concatenação de todos esses elementos que se pode abordar a reinvenção contínua da privacidade.

Por certo, existe uma grande distância entre o que é tido hoje como particular, e como ele é tratado no cotidiano presencial e online, daquela concepção que emergiu na Idade Média. Da mesma forma, a escolha, manutenção e rompimento de amizades respondem agora a distintos desejos e anseios. Pode-se especular que a circulação de selfies remediam as pinturas em miniaturas, que as mensagens privadas online (via e-mail, mensageiros instantâneos, $\mathrm{DMs}^{4}$, etc.) remediam as cartas e até mesmo que perfis não-públicos em sites de redes sociais remediam aquilo que o quarto e a ruelle ${ }^{5}$ vieram a tornar-se na Idade Média. Sem querer promover comparações forçadas, este artigo pretende a seguir discutir como o privado vem sendo hoje vivenciado e como conversas particulares são mantidas em sigilo ou até mesmo publicizadas abertamente.

\section{As fronteiras do público e do privado na contemporaneidade}

Apesar de termos até o momento apresentado o privado como se fosse simplesmente a antítese de tudo aquilo que é público, é importante neste momento reconhecer que as fronteiras que separam os espaços público e privado encontram-se cada vez mais tênues em tempos de hiperexposição da vida em redes digitais. A oposição dessas esferas, que consistem de uma invenção histórica convencionada pelo mundo Ocidental (SIBILIA, 2003; GOODMAN,1992), vêm sendo atenuadas. Estes domínios têm se mostrado cada vez mais interdependentes, através da mediação entre o público e o privado realizada pelas tecnologias de comunicação (BRUNO, 2005). Como seu viu, a intimidade e a esfera privada da vida cotidia-

\footnotetext{
${ }^{4}$ DM é uma abreviatura para "direct message". Trata-se do serviço de mensagens privadas entre duas pessoas no Twitter.

${ }^{5}$ Ruelle era o espaço entre a cama e a janela, onde podia-se manter a privacidade de conversas.
} 
na não tinham relevância até a Idade Média, quando a burguesia europeia sentiu a necessidade de um refúgio para o indivíduo e para a família (SIBILIA, 2003; ARIÈS, 1991; CASTAN, 1991). 0 chamado "muro da vida privada" (CASTAN, 1991, p. 413) separava as relações familiares, de amizade e liberdade das coerções e regras da vida pública. Atualmente, esse muro parece ceder lugar a uma cultura em que a vida privada busca um olhar que a reconheça e ateste a sua visibilidade (BRUNO, 2005). Já Bauman (2013, p.33) entende que "a privacidade invadiu, conquistou e colonizou o domínio público". Nesse sentido, vivemos hoje em um mundo bastante distinto daquele dos tempos medievais. Da invenção do particular naquela era até hoje, o privado vem passando por inúmeras transformações até o ponto em que transborda e invade aquilo que se supunha seu oposto: o público.

Diante do progressivo atravessamento entre público e privado, as redes digitais contribuem para a consolidação do que Maia (2008) chama de esfera pública virtual. Com protocolos específicos, práticas, liberdades e regramentos próprios, tem-se uma relação recursiva em que o público se alimenta do que é privado (e vice-versa), integrando-se a uma esfera pública midiática 6 que é "entregue em domicílio, penetrando em espaços tradicionalmente privados e afirmando-se como o médium por excelência que conecta o público e o privado" (BRUNO, 2005, p.55).

Para além da mera evolução tecnológica, Bauman (2013) aponta que a erosão do anonimato é produto da mudança na visão das pessoas sobre o que deve ser público e o que deve ser privado. Há um consentimento na perda dos direitos de privacidade por vontade própria ou pelas vantagens que podem ser obtidas. Com essa alteração na concepção de privacidade, conclui o autor, é possível que não haja mais prazer em manter segredos,

[...] a menos que sejam do tipo capaz de reforçar nossos egos atraindo a atenção de pesquisadores e editores de talk shows televisivos, das primeiras páginas dos tabloides e das capas das revistas atraentes e superficiais. (BAUMAN, 2013, p. 34).

Enfim, com a proliferação da internet móvel e de aplicativos para a comunicação interpessoal, a conexão ubíqua se adaptou de tal forma à rotina dos sujeitos que as noções de espaço público e privado se tornam difusas. Como se verá adiante, não raro mensagens particulares acabam sendo circuladas em grupos maiores, seguindo uma lógica de espetáculo ou como vazamentos de conteúdos íntimos. Logo, a partir da reflexão sobre a mudança de concepção sobre o público e o privado no atual cenário, este artigo passa agora a revisar

${ }^{6}$ Bruno (2005) explica que a esfera pública midiática está ligada à onipresença e à mediação da realidade pelas tecnologias de comunicação. 
uma série de protocolos de sociabilidade que visam evitar problemas quanto à produção e circulação de mensagens privadas.

\section{Protocolos de sociabilidade em trocas de mensagens privadas}

Protocolos de sociabilidade configuram maneiras convencionadas de agir e de se comportar em determinado contexto. Tais normas de conduta, conforme veremos ao longo deste tópico, são distintas para cada época e ambiente onde acontecem.

Como se viu anteriormente, a literatura de civilidade é um dos marcos da progressiva privatização da vida medieval (ARIÈS, 1991). Tal gênero literário é composto por manuais de comportamento, regras de etiqueta, códigos de conduta, guias de bom tom, etc., e busca "ensinar o que é ou o que deve ser civilizado" (CUNHA, 2006, p. 351). De acordo com Cecchin e Cunha (2007), civilizar-se em sociedade seria conduzir o comportamento "a uma normatização de atitudes a fim de moldar posturas, desde a primeira hora do dia até o momento de recolher-se para o descanso" (p. 2). Ou seja, tanto em âmbito privado, quanto público, há determinados protocolos para regulamentar a convivência social.

No que se refere à conversação, um dos manuais de civilidade mais conhecidos é do filósofo iluminista francês André Morellet (2002). Seus ensaios descrevem e criticam os vícios que prejudicariam a prazerosa arte de conversar. Morellet, frequentador dos salões franceses do século XVIII, via a conversação como uma arte que não era dominada por muitos. Ao listar os problemas que percebia nos diálogos da sociedade francesa setecentista, propunha aclarar as normas de conduta para que as interações entre aqueles homens fluíssem de forma mais prazerosa. Para Goulemot (1991), os manuais de civilidade tinham a função de "impor novas condutas através dos modelos altamente valorizados e para excluir necessariamente do espaço público comportamentos que outrora lhe pertenciam" (1991, p. 372).

Por mais que a circulação de tais manuais normativos possam causar estranheza ao leitor contemporâneo, vale lembrar que livros de etiqueta permanecem sendo lançados por importantes editoras. E mesmo na internet, onde supõe-se haver total liberdade, regras de conduta para a conversação online estão presentes desde a criação de mensagens privadas e dos primeiros fóruns de discussão.

Enquanto a internet ainda era acessada por poucos, em sua maioria pessoas ligadas à computação, e como a conexão discada da época era por demais cara e lenta, algumas regras começaram a ser organizadas para se otimizar a interconexão. Algumas boas práticas para a 
redação de mensagens passaram a ser sugeridas e compartilhadas - por exemplo, usar assinaturas curtas, evitar longas citações e anexos (ELLIS, 2010).

O neologismo "netiqueta" é então criado a partir da junção das palavras "internet" e "etiqueta". 0 termo surge em fóruns de discussão da Usenet ${ }^{7}$ para determinar o conjunto de convenções e boas maneiras que seus participantes deveriam seguir ao publicar nos grupos de notícias (KEHOE, 1992). Nesse sentido, a netiqueta remedia os antigos manuais de conversação e civilidade. Enquanto no período medieval tais manuais visam regrar os modos à mesa e as práticas de hospitalidade, a netiqueta é criada inicialmente para resolver problemas técnicos da circulação de mensagens digitais.

Com a popularização da Usenet, regras de conduta passaram a incluir procedimentos para facilitar a leitura das postagens, como evitar assinaturas longas, não enviar mensagens pessoais nos grupos, evitar "cross posting"8, "multiposting", ou qualquer prática que caracterizasse flood $^{10}$. Tais orientações serviam para manter a organização dos tópicos e prevenir que atitudes divergentes prejudicassem a compreensão do artigo ou da discussão. A regras convencionadas originalmente para a Usenet foram progressivamente adequadas à comunicação via e-mail, blogs, fóruns e em outros tipos de serviços online. E, como se encontra em Jones (2003), como a internet não tem um centro controlador, tais regras de convivência são mantidas e aplicadas pela própria comunidade.

Em 1995, o Internet Engineering Task Force (IETF), um coletivo que surgiu em 1986 com o objetivo de "fazer a internet funcionar melhor"11, publicou um artigo chamado Netiquette Guidelines (1995). 0 documento foi elaborado por um grupo chamado RUN (Responsible Use of the Network), participante do IETF, e tinha por objetivo orientar novos usuários que ainda não estivessem habituados com a cultura da internet. 0 guia trazia observações acerca da comunicação um-a-um e um-para-muitos. Ao utilizar o e-mail, por exemplo, o manual recomendava que: não se utilize apenas maiúsculas - ou o destinatário poderia pensar que o remetente está gritando; não se modifique a mensagem original ao encaminhá-la para outra pessoa; não se inclua destinatários em cópia em mensagens que já estão sendo trocadas - a menos que os outros participantes da conversação estejam de acordo - já que o

\footnotetext{
${ }^{7}$ Usenet é uma plataforma em que os participantes podem postar artigos, no formato texto em fóruns classificados por assunto, chamados de newsgroups, ou, em português, grupos de notícias. A palavra é uma junção dos termos Unix User Network

${ }^{8}$ Cross posting é o ato de enviar a mesma mensagem em diversos grupos de notícias diferentes, buscando fazer com que aquela mensagem chegue ao maior número de pessoas possível.

${ }_{9}^{9}$ Multiposting é o ato de enviar a mesma mensagem diversas vezes no mesmo grupo de notícias ou fórum, em um curto espaço de tempo

${ }^{10}$ Flood é um termo usado para indicar excesso de postagens sucessivas feitas por um mesmo usuário.

11 No original, "make the internet work better".
} 
histórico de e-mails ficaria visível para todos. 0 documento abordava até o uso de "smileys" (ou emoticons), como “:-)", para auxiliar a interpretação do tom das mensagens enviadas.

Mais recentemente, pode-se encontrar artigos sobre como se comportar nos sites de redes sociais, serviços estes que passam a se popularizar nos anos 2000. Buzzfeed (HEANEY, 2015), Tecmundo (HAMANN, 2015) e youPIX (SANSEVERINI, 2015) são exemplos de sites que publicaram listas de atitudes a serem evitadas no Facebook e no Twitter. No Facebook, convites para jogos, indiretas pessoais e pedidos de curtidas são atitudes condenadas. No Twitter, artigos sobre etiqueta na rede frequentemente criticam práticas como excesso de hashtags e tuítes com links sem descrição.

Mesmo que os protocolos de sociabilidade variem em cada serviço online, pode-se perceber que muitas das normas se mantém vigentes, principalmente em se tratando de interações em grupos. Fóruns de discussão frequentemente apresentam normas de comportamento aos recém-chegados, muitas delas herdadas da netiqueta dos tempos da Usenet. Mensagens em caixa alta, postadas seja de forma pública ou privada, podem ainda ser interprestadas como gritos. No Twitter e no Facebook, o excesso de hashtags é condenável sob a ótica dos usuários mais antigos. Isso não quer dizer, evidentemente, que tais normas sejam leis intransponíveis. 0 uso de muitas hashtags, por exemplo, é normal e bem aceito no serviço Instagram, especializado na circulação de fotografias digitais.

Em plataformas de conversação abertas, como IRC e chats de portais, após a escolha do canal ou sala de bate-papo, pode-se iniciar conversações com desconhecidos. Como não se sabe quem é a pessoa com quem se está falando, é recomendado não fornecer dados pessoais, como nome completo, número de telefone, endereço, etc. - pelo menos nos primeiros contatos. Por outro lado, em certos canais (como "Pulando a cerca", no qual pessoas casadas buscam sexo eventual), encontrar desconhecidos é justamente o objetivo pretendido.

No que concerne aos mensageiros instantâneos (IMs), os protocolos de convivência mais difundidos estão relacionados à segurança. Em serviços como ICQ e MSN Messenger, a conexão entre duas pessoas acontecia somente se uma delas obtivesse ao menos o e-mail (ou nome de usuário, ou número da conta, no caso do ICQ) da pessoa, e esta aceitasse a conexão. Mesmo assim, não raro aceitava-se pessoas desconhecidas para figurarem nas listas de contatos. Ou seja, as normas de conduta para que não se forneça dados pessoais nos primeiros contatos permaneceram também nesses serviços. Um diferencial desses serviços é que era possível bloquear contatos que porventura cometessem algum tipo de abuso. Recurso semelhante é adotado em diversos serviços subsequentes. 
Mesmo em aplicativos mais recentes os usuários são cuidadosos com o tipo de informação que vão fornecer sobre si e para marcar os primeiros encontros. No uso do Tinder ${ }^{12}$, o serviço não oferece muitas informações sobre os contatos, somente o primeiro nome e os possíveis amigos e interesses em comum (dados obtidos pelo aplicativo através da conexão com o Facebook). Embora o objetivo do serviço seja a busca de parceiros sexuais, muitas pessoas têm receio de marcar o primeiro encontro em locais isolados, como na casa do parceiro ou em sua própria casa.

É preciso observar que os protocolos de sociabilidade mantém-se em estado de fluxo, em acordo com o desenvolvimento das tecnologias de comunicação e suas comunidades. Enquanto no Twitter postar fotos de refeições, cafés e doces seja motivo de piada, no Instagram tais imagens tem espaço quase protagonista, tanto que uma das hashtags mais populares do serviço é \#instafood. Além disso, a invenção da expressão pejorativa "orkutização" evidenciou que o protocolo social de uma determinada rede pode não funcionar em outra. 0 termo está relacionado a algumas práticas de usuários mais recentes do Facebook que, ainda não acostumados com a cultura do site, trouxeram consigo maneiras de se comunicar similares àquelas que utilizavam no Orkut, o que não foi bem-visto pelos usuários mais antigos do site (LUPINACCI et al., 2015). Isso mostra que o que é apropriado em determinado contexto pode ser inadequado em outros lugares e situações interativas.

Também no Orkut, a área destinada para os depoimentos - que, originalmente, serviriam para que um usuário escrevesse uma homenagem a outro - acabou sendo apropriada para o envio de mensagens privadas ${ }^{13}$ (LUPINACCI et. al, 2015). A publicação (acidental ou não) de conteúdos particulares, que normalmente continham o aviso "NÃO ACEITA", configurava uma quebra do protocolo de uso estabelecido naquele site e, dependendo do conteúdo da mensagem - que poderia ainda ser compartilhada com intuito humorístico em páginas especializadas como a "Pérolas do orkut"14 — podia gerar grandes constrangimentos.

Enfim, como se viu nos exemplos contemporâneos e da Idade Média, os manuais de civilidade e etiqueta são também formas de controle e manutenção de modos de convivência. Ao privar-se de realizar determinada atividade por uma questão de civilidade, entende-se que esta atividade poderia prejudicar a convivência ou desrespeitar a harmonia social. En-

\footnotetext{
12 Tinder é uma plataforma móvel de localização de pessoas geograficamente próximas para encontros românticos através da conexão com o Facebook.

13 Para tanto, o dono do perfil não deveria aprovar a publicação do depoimento após sua leitura.

14 Que atualmente se dedica à publicação de mensagens risíveis de diversos sites, como Facebook, Twitter e Yahoo! Respostas, e pode ser acessado em <http://perolas.com/>.
} 
tretanto, com a sucessão de casos de abusos em sites e aplicativos de relacionamento, muitas campanhas em veículos da grande mídia (GOULART, 2012), portais de notícia (IKEDA, 2012) e até mesmo marcas (PASSOS, 2015) passaram a alertar para o tipo de conteúdo compartilhado nessas plataformas, como vídeos e fotos íntimas. Tais matérias têm como escopo a prevenção de problemas da internet, mas com frequência aconselham a audiência a não produzir conteúdo íntimo. A mídia evidencia, assim, um direcionamento muito mais moralista do que preventivo. Prefere criticar quem produz material íntimo em vez de condenar quem compartilha sem autorização conteúdo particular de terceiros.

A seguir, discute-se justamente o "vazamento" de mensagens privadas. Ou seja, quando os protocolos de convivência online são rompidos.

\section{Caiu na net: quando conteúdos de conversas privadas são trazidos a público}

Muitas vezes as normas de conduta que guiam o uso dos serviços de comunicação online não são respeitadas. Esta seção trata justamente da quebra desses protocolos, quando materiais íntimos saem de conversas privadas e passam a circular publicamente. Com isso, pretende-se problematizar questões de privacidade, intimidade e segurança no que tange ao uso de ferramentas de conversação online.

No primeiro semestre de 2015, o meme 15 "manda nudes" tornou-se muito popular em diferentes plataformas de sociabilidade (MAIA, 2015). "Manda nudes" faz referência ao pedido de alguém para que o outro envie fotos sem roupa. Esse tipo de solicitação, que aparece com variados níveis de sutileza ao longo da trajetória de usos de ferramentas online - como, por exemplo, "tem cam?", típico de chats e do MSN Messenger - normalmente é feito em conversas privadas, através de plataformas que permitem conversação de um para um. No entanto, em março de 2015, "manda nudes" começou a aparecer com grande frequência no Twitter, em um contexto bem-humorado no qual os usuários fazem montagens e pedem fotos de nudez através da apropriação de conteúdos da cultura pop. Foi inclusive criado um tumblr em que as melhores versões do meme são compiladas. Apesar de se inserir na lógica da "zueira" (BARBOSA, 2015), que se alastrou pela web brasileira nos últimos anos, a crescente circulação do meme é também um indício de que o envio de conteúdos íntimos conti-

\footnotetext{
${ }^{15}$ Memes podem ser entendidos como pedaços de informação cultural que passam de pessoa para pessoa através de processos de propagação gradual e reprodução via cópia e imitação. No contexto atual, o termo "meme" é usualmente aplicado para tratar de apropriação de ideias ou produtos culturais, normalmente na forma de imagens, vídeo ou texto, que são rapidamente propagados, sofrendo transformações conforme circulam (SHIFMAN, 2014)
} 
nua sendo amplamente praticado (e requisitado) nas conversações mediadas por computador, o que requer uma continuidade na discussão sobre privacidade na internet.

A discussão sobre a circulação de conteúdos considerados íntimos no ambiente online vem de longa data, já que diferentes plataformas foram apropriadas para a exposição da intimidade e para fins eróticos. Segundo Senft (2008), estamos inseridos em uma cultura altamente mediada, e não deveria surpreender, ainda hoje, que as pessoas utilizem as tecnologias como recurso para expressão subjetiva e sexual. Um exemplo de apropriação de uma ferramenta para exposição da intimidade é o ChatRoulette. Trata-se de um site criado em 2009 que permite conexões via webcam com usuários desconhecidos e aleatórios. Funciona como uma roleta russa, pois o usuário nunca sabe quem estará do outro lado da interação (CRUZ; MENEZES, 2012). A efemeridade da conexão, o fato de o outro interagente ser desconhecido e a possibilidade de esconder o rosto com o posicionamento estratégico da câmera, ou mesmo com o uso de máscaras, foram alguns dos fatores que tornaram o site atrativo para atividades de exibição, nudez e exposição sexual (SAUTER, [2011]).

Uma prática bastante comentada atualmente é o sexting ${ }^{16}$, que consiste do ato de enviar mensagens, imagens ou vídeos sexualmente sugestivos, frequentemente apresentando nudez total ou parcial. Tipicamente, alguém tira uma foto ou grava um vídeo de si mesmo e, então, envia esse conteúdo para outra(s) pessoa(s) (POLTASH, 2013). De acordo com Poltash (2013), apesar da atual popularidade do WhatsApp, o software que reuniria as melhores qualidades para a prática de sexting seria o Snapchat ([2015]). Trata-se de um aplicativo para dispositivos móveis em que seus usuários podem trocar mensagens (fotografia, vídeo ou texto). Cada mensagem pode ser visualizada por poucos instantes - de 1 a 10 segundos, sendo o tempo de exibição determinado pelo usuário que faz o envio. E, após a sua visualização, as mensagens enviadas são deletadas - não apenas do aparelho de quem as recebeu, como também dos servidores da empresa. Assim, a autora avalia que o Snapchat confere a seus usuários uma falsa sensação de segurança, dando liberdade para que eles enviem fotos comprometedoras sob a ilusão de que essas desaparecerão após instantes - o que fez com que o aplicativo fosse, desde seu lançamento, utilizado para sexting. Porém, apesar de o Snapchat prometer o "apagamento" das mensagens após a visualização, existem alternativas que permitem o acesso aos arquivos por mais tempo: os usuários podem fazer screenshots (captura da tela como imagem), ainda que isso gere uma notificação para o emissor. Podem, também, tirar fotos das telas de seus celulares, o que contorna a notificação ativada pelo

16 Termo originado da junção das palavras sex (sexo) e texting (envio de mensagens). 
screenshot. Há ainda soluções mais complexas, como a recuperação dos conteúdos (que ficam salvos na memória local do celular) com a utilização de vasculhadores de arquivo especializados (POLTASH, 2013).

O compartilhamento de materiais sensíveis implica em um risco de que esses conteúdos sejam circulados para além do desejo e do controle do sujeito que aparece neles. Por mais privada que seja a conversa na qual se dá o compartilhamento original, existe sempre a chance de que alguém vaze esses materiais, tornando-os disponíveis para acesso público. Entendemos que esses vazamentos de exposição pública da intimidade podem ser de três tipos: (1) não consensual por vingança, (2) não consensual feito por terceiros e (3) intencional.

No vazamento não consensual por vingança, os conteúdos são trazidos a público por pessoas próximas à vítima, como forma de retaliação - por isso a prática é frequentemente chamada de revenge porn (ou pornografia de vingança). Na maioria das vezes, esses materiais - normalmente fotos ou vídeos - são divulgados por antigos parceiros, que receberam os conteúdos durante o relacionamento e os mantiveram após o fim da relação (LAIRD, 2013). Um dos casos mais famosos é o de Paris Hilton, que em 2004 teve um vídeo erótico caseiro divulgado, sem seu consentimento, por seu ex-namorado (MCLAUGHLIN, 2011). Não raro, esses conteúdos não-autorizados são postados juntamente com o nome, a cidade e até com links para o perfil da vítima em sites de rede social - o que pode prejudicar essa pessoa de inúmeras formas, desde a dificuldade em conseguir emprego até na insegurança para construir futuros relacionamentos (LAIRD, 2013). Se antes da popularização da internet a prática de entregar fotos íntimas para o parceiro trazia relativamente poucos riscos, hoje a chance de perder-se o controle sobre esses materiais é muito maior, ainda mais considerando a existência de plataformas que tem como único intuito divulgar esses conteúdos (LAIRD, 2013).

Já o vazamento não consensual feito por terceiros consiste da circulação de conteúdos íntimos que é iniciada por alguém externo à conversação na qual os materiais foram originalmente compartilhados - alguém que não esteve envolvido no envio original da mensagem, nem como emissor, nem como destinatário. Normalmente, esse tipo de vazamento é feito por crackers $^{17}$, que acessam e publicam ilegalmente conteúdos íntimos alheios. Em 2014, fotografias contendo nudez e poses sexualmente sugestivas de uma grande quantida-

${ }^{17}$ Cracker, do inglês "aquele que quebra", é um termo que designa indivíduos que possuem grandes conhecimentos técnicos na área da informática e que usam esse conhecimento para acessar ilegalmente sistemas de segurança com fins criminosos, frequentemente praticando roubos e atos de vandalismo em benefício próprio. 
de de celebridades foram disponibilizadas online. As vítimas do vazamento incluíam artistas famosas, como a atriz Jennifer Lawrence, que em comunicado oficial disse ter tirado as fotos para enviar exclusivamente para seu então namorado (D’AMICO, 2014). O'Connor (2014) aponta que, apesar desse episódio não ter sido o primeiro incidente de publicação nãoautorizada de fotos privadas de celebridades, o evento é marcante por suas proporções. Segundo as investigações, essas imagens foram roubadas das contas pessoais das vítimas no iCloud, serviço de armazenagem da Apple. Poucas semanas depois, foram trazidas a público pelo menos 100 mil fotos enviadas pelo Snapchat que foram interceptadas por criminosos. Essas imagens, de pessoas comuns e não-famosas, foram parar no site $4 \operatorname{chan}^{18}$, onde foi criada uma base catalogada e pesquisável, na qual era possível encontrar facilmente fotos buscando por usernames do Snapchat. Nesse caso, os problemas éticos foram ainda maiores, já que muitas das imagens eram de meninos e meninas menores de idade (O'CONNOR, 2014).

É preciso considerar ainda os casos em que o vazamento é feito intencionalmente pelo sujeito que aparece nos conteúdos publicados, seguindo a lógica da exposição consensual da privacidade apontada por Bauman (2013), comentada anteriormente. Trata-se da publicação premeditada de conteúdos comumente considerados íntimos, em que abre-se mão da privacidade tendo em vista uma rápida obtenção de visibilidade e fama - ou seja, do uso do privado como negócio. Portanto, não são tecnicamente "vazamentos" e sim a exposição proposital de conteúdos considerados íntimos, frequentemente simulando uma publicação acidental. Segundo Lana (2014), os estudos mais recentes dos Celebrity Studies tem apontado que é cada vez menos provável que as pessoas consigam manter visibilidade midiática sem gerir estrategicamente sua imagem. Nesse sentido, o vazamento intencional com fins mercadológicos é comumente associado à celebridades que tentam produzir "pseudoacontecimentos" com a finalidade de gerar divulgação (LANA, 2014).

Ainda no que se refere à exposição mercadológica do corpo e da intimidade em plataformas digitais, é importante comentar a produção das camgirls - mulheres que transmitem suas vidas ao vivo pela web, normalmente cobrando por tempo de visualização (SENFT, 2008). Senft (2008) chama a técnica empregada pelas camgirls de homecamming: uma transmissão conduzida a partir de uma esfera doméstica, em que tende-se a posicionar pelo menos uma câmera dentro do quarto. A mais famosa das camgirls foi Jennifer Ringley, que exibia continuamente na web imagens de sua vida privada, incluindo a transmissão de relações sexuais com seu então namorado. Seu site JenniCam conquistou uma grande audiência,

${ }^{18}$ Disponível em: http://www.4chan.org/(acesso em 15/09/2015). 
alcançando mais de 100 milhões de acessos por semana em seu auge, em 1998. Hoje, são poucas as camgirls que ainda se mantêm ativas - o site JenniCam, por exemplo, saiu do ar em 2004 (SENFT, 2008). Para a autora, as camgirls, enquanto "celebridades" da web, compartilham uma característica muito importante com as estrelas da mídia tradicional: ambas precisam trabalhar suas marcas e criar constantemente ações mercadológicas. Caso contrário, não conseguem reter a atenção de suas audiências e da própria mídia. E, dentre as ações possíveis, a exposição da vida privada, da intimidade e da sexualidade parece ser uma opção tentadora, devido a seus baixos custos e a sua grande capacidade de atrair, ainda hoje, o interesse público.

Apesar dessa tipologia construída dar conta da maioria dos casos de vazamento de conteúdos íntimos, é preciso ressaltar que as categorias não são estanques, e que às vezes é até difícil de determinar a real motivação por trás de alguns casos, havendo dúvidas sobre a intencionalidade ou não da circulação desses materiais. Além disso, é preciso considerar também que alguns casos podem transitar por mais de uma categoria, já que algumas das vítimas de vazamentos não consensuais acabaram utilizando esses acontecimentos a seu favor, exercendo também uma mercantilização - Kim Kardashian, por exemplo, é muito mais popular hoje do que antes do vazamento de seu vídeo íntimo por seu ex-namorado, o que aconteceu em 2003.

Mas o fato é que quando a circulação de imagens íntimas não é intencional, as consequências para a vítima podem ser desastrosas. E, apesar de reconhecerem que se trata de um crime e de um ataque à privacidade alheia, muitas pessoas que comentam esse tipo de incidente atribuem uma parcela da culpa à própria vítima - já que, em algum momento, esta consentiu em aparecer em poses sensuais na frente de uma câmera (O'CONNOR, 2014; D'AMICO, 2014). No caso das celebridades que tiveram sua intimidade violada por crackers, críticos costumam dizer que, uma vez que essas pessoas são personalidades da mídia portanto, pessoas públicas - , deveriam tomar mais cuidado com o que fazem, mesmo em suas vidas privadas (O'CONNOR, 2014). E, na imprensa, a solução apontada para evitar esse tipo de incidente normalmente se dirige às próprias vítimas: para se proteger, bastaria não produzir e enviar esse tipo de imagem comprometedora (MACHADO, 2015). Como se viu anteriormente, culpa-se a vítima a partir de uma ótica moralista. 


\section{Considerações Finais}

Apesar de não empreender uma completa arqueologia da vida privada, este artigo pôde apresentar um contraste entre as práticas e lugares privados online com o nascedouro da concepção de privacidade e a constituição de espaços para o particular na Idade Média. Claro, as amizades e amores de hoje são muito diferentes daqueles do Antigo Regime, e muitos séculos de transformações separam essas duas eras. Nesse percurso, a vida privada esteve e continua em permanente processo de transformação. Hoje, a onipresença das tecnologias digitais permite que encontros privados aconteçam em qualquer lugar e instante. Enquanto o gabinete e os jardim fechados apareceram como loci possível para o gozo de momentos solitários e para conversas privadas, os smartphones permitem converter-se qualquer lugar em um ponto de encontro virtual para conversas privadas. Curiosamente, esta disponibilidade "always on" com frequência põe em conflito uma conversa particular via Facebook Messenger com o encontro presencial (em um restaurante, por exemplo), colocando em espera o parceiro presente no mesmo espaço geográfico.

Outro problema recorrente é a falsa ilusão de privacidade que sites de redes sociais oferecem. Mesmo que alguém evite o acesso livre ao seu perfil no Facebook, nunca se sabe ao certo quem está de fato lendo suas publicações. Uma mensagem em um grupo fechado pode ter seu caráter privado violado à medida que é repassada para outras pessoas, distantes do contexto original de produção daquele conteúdo. Em muitos casos de "vazamentos", que rompem com protocolos tácitos de convivência online, o ambiente digital acaba funcionando como um tribunal, no qual a audiência usa compartilhamentos e comentários para julgar os envolvidos.

Enfim, não se pode supor que qualquer regramento sobre comportamentos públicos ou privados, online ou offline, sejam válidos para qualquer grupo, tempo ou lugar. Tanto os primeiros manuais de conversação medievais quanto os diversos textos de netiqueta respondem a certas intenções e motivações localizadas. No caso das normas de convivência online, foi possível observar como buscam responder a limitações técnicas (baixa largura de banda, falta de pistas não-verbais ${ }^{19}$ ), evitar potenciais conflituosos e proteger a intimidade. Contudo, como qualquer norma, os ditames das diferentes propostas de netiqueta valem em certos casos, em certas circunstâncias e entre certos interagentes. Escrever um texto em maiúsculas não quer dizer necessariamente que se esteja gritando - em certos contextos,

${ }^{19}$ Os smileys ou emoticons foram desenvolvidos justamente para demonstrar o contexto afetivo da redação da mensagem. 
como no radiojornalismo, é assim que textos devem ser escritos. Certos comportamentos de uma mesma pessoa podem ser valorizados em um site de rede social e criticados em outro serviço online. "Mandar nudes" não consiste em grave pecado moral entre inúmeros parceiros e amigos. Como visto anteriormente, a circulação intencional de imagens íntimas pode inclusive fazer parte de uma estratégia mercadológica. Portanto, o leitor desavisado não deve concluir que este artigo faz uma defesa da necessária proteção da intimidade. 0 que buscou-se aqui foi discutir como a privacidade vem sendo reinventada e narrada, como depende de circunstâncias culturais e das formas interativas utilizadas. Além disso, demonstrou-se também como a estreita fronteira entre o privado e o público cada vez mais caduca nas práticas e na teoria.

\section{Referências}

ARIÈS, Philippe. Por uma história da vida privada. In: ARIÈS, Philippe; CHARTIER, Roger (Org.) História da vida privada: da Renascença ao Século das Luzes. São Paulo: Companhia das Letras, 1991. p. 7-19

AYMARD, Maurice. Amizade e convivialidade. In: Ariès, Philippe; Chartier, Roger (Org.). História da vida privada vol. 3: da Renascença ao Século das Luzes. São Paulo: Companhia das Letras, 1991.

BARBOSA, Camila Cornutti. Celebridades e apropriações humorísticas em blogs: uma análise do Morri de Sunga Branca e do Te Dou um Dado? 2015. Tese (Doutorado em Comunicação e Informação) - Programa de Pós-Graduação em Comunicação e Informação, Universidade Federal do Rio Grande do Sul, Porto Alegre, 2015.

BAUMAN, Zygmunt. Vigilância Líquida: diálogos com David Lyon. Rio de Janeiro: Zahar, 2013.

BOLTER, Jay David; GRUSIN, Richard. Remediation: understanding new media. Cambridge: MIT , 2000.

BRUNO, Fernanda. Quem está olhando? Variações do público e do privado em weblogs, fotologs e reality shows. Contemporanea, Salvador, v. 3, n. 2, p 53-70. jul./dez. 2005.

CASTAN, Nicole. 0 público e o particular. In: ARIÈS, Philippe; CHARTIER, Roger (Org.) História da vida privada: da Renascença ao Século das Luzes. 1991. p. 413-453

CECCHIM, Cristiane; CUNHA, Maria Teresa S. Tenha modos! Educação e sociabilidade em manuais de etiqueta (1900-1960). In: SIMPÓSIO INTERNACIONAL PROCESSO CIVILIZADOR, 10., 2007, Campinas. Anais... Campinas: Unicamp, 2007. 
CHARTIER, Roger. Formas da privatização: Introdução. In: ARIÈS, Phillippe; CHARTIER, Roger (Org.). História da vida privada: da Renascença ao Século das Luzes. São Paulo: Companhia das Letras, 1991. p. 165-167

CRUZ, Nayara Takahara; MENEZES, Maurelio. A manifestação da sexualidade na Internet: o caso ChatRoulette. In: Congresso Brasileiro de Ciências da Comunicação, 35., 2012, Fortaleza. Anais... Fortaleza: Intercom, 2012.

CUNHA, Maria Teresa Santos. Tenha modos! Manuais de civilidade e etiqueta na escola normal. (1920-1960). In: CONGRESSO LUSO-BRASILEIRO DE HISTÓRIA DA EDUCAÇÃO, 6., 2006, Uberlâncida. Anais... Uberlândia, 2006.

D'AMICO, Elisa. Solution for celebrity nude photo hack is obvious: keep files out of cloud. Daily Business Review, [S.l.], 2014. Disponível em: <http://at.law.com/3vA2Ue>. Acesso em: 27 nov. 2015.

ELLIS, R. Stewart. A brief history of the internet (\& email etiquette). 2010. Disponível em: <http://paws.kettering.edu/ ellis/brief-hist-internet-netiq.htm>. Acesso em: 15 set. 2015.

GOODMAN, Deena. Public sphere and private Life: toward a synthesis of current historiographical approaches to the old regime. History and Theory, v. 31, n.1, p. 1-20, Fev. 1992.

GOULART, Marina. Aprenda a evitar vazamento de arquivos pessoais na internet. Zero Hora, 2012. Disponível em:

<http://zh.clicrbs.com.br/rs/noticias/noticia/2012/05/aprenda-a-evitar-vazamentos-dearquivos-pessoais-na-internet-3750838.html> Acesso em: 15 set. 2015.

GOULEMOT, Jean Marie. As práticas literárias ou a publicidade do privado. In: ARIÈS, Philippe; CHARTIER, Roger (Org.). História da vida privada: da Renascença ao Século das Luzes. São Paulo: Companhia das Letras, 1991. p. 371-405

HABERMAS, Jürgen. Mudança estrutural da esfera pública: investigações quanto a uma categoria da sociedade burguesa. Rio de janeiro: Tempo Brasileiro, 2003.

HAMANN, Renan. 5 coisas que você não deve fazer no

Facebook. Tecmundo, [S.I.], 2012. Disponível em:

<http://www.tecmundo.com.br/facebook/24317-5-coisas-que-

voce-nao-deve-fazer-no-facebook-ilustracao-.htm>. Acesso em:

15 set. 2015.

HEANEY, Katie. 11 things you should never, ever do on Facebook. Buzz Feed News, [S.l.], 2011. Disponível em: <http://www.buzzfeed.com/katieheaney/11-things-you-shouldnever-ever-do-on-facebook\#.jxywomGq7r>. Acesso em: 15 set. 2015.

INTERNET Engineering Task Force. [Site]. 1986. Disponível em:< http://www.ietf.org $>$. Acesso em: 15 set. 2015. 
IKEDA, Ana. Fotos íntimas caem na internet: saiba como evita exposição e reduzir danos. Uol Tecnologia, 2012. Disponível em:

<http://tecnologia.uol.com.br/noticias/redacao/2012/05/10/caso-carolina-dieckmannexposicao-de-fotos-intimas-e-comum-saiba-como-evitar.htm> Acesso em: 15 set. 2015.

JONES, Steve. Encyclopedia of new media: an essential reference to communication and technology. Thousand Oaks: Sage, 2003.

KEHOE, Brendan P. Zen and the art of the internet-a beginner's guide to the Internet. 1992. Disponível em: <https://www.cs.indiana.edu/docproject/zen/zen-1.0_toc.html>. Acesso em: 15 set. 2015.

LAIRD, Lorelei. Striking back at revenge porn: victims are taking on Websites for posting photos they didn't consent to. ABA Journal, Chicago, p. 44-47, 2013.

LANA, Lígia. Celebridade, humilhação e moral sexual: a vice-miss bumbum avaliada por comentários do Youtube. In: CONGRESSO BRASILEIRO DE CIÊNCIAS DA COMUNICAÇÃO, 37. 2014, Foz do Iguaçu. Anais... Foz do Iguaçu: Intercom, 2014.

LENHART, Amanda et al. Eletronic comunication. Pew Research Center, Washington, Apr. 2008. Disponível em: < http://www.pewinternet.org/2008/04/24/electroniccommunication/> Acesso em: 15 set. 2015.

LUPINACCI, Ludmila; BARROS, Laura; VALIATI, Vanessa; PRIMO, Alex. \#RIPorkut: a reação dos usuários brasileiros ao fim desse site que a gente conhecia bem e considerava pakas. In: ENCONTRO NACIONAL DE HISTÓRIA DA MÍDIA, 10., 2015, Porto Alegre. Anais... Porto Alegre: ALCAR, 2015.

MACHADO, Nealla Valentim. "Caiu na net", Sexting e as imagens íntimas na mídia online brasileira. In: CONGRESSO DE CIÊNCIAS DA COMUNICAÇÃO NA REGIÃO CENTRO-OESTE, 27., Campo Grande, 2003. Anais... Campo Grande, 2015.

MAIA, Leo. Tumblr do dia: manda nude. YouPix, [S.l.], 2015. Disponível em: <http://youpix.virgula.uol.com.br/tumblr-2/tumblr-do-dia-manda-nude/>Acesso em: 15 set. 2015.

MAIA, Rousiley Celi Moreira. Democracia e a internet como esfera pública virtual: aproximação às condições da deliberação. In: GOMES, Wilson; MAIA, R. Comunicação e democracia: problemas e perspectivas. São Paulo: Paulus, 2008.

McLAUGHLIN, Katie. Paris Hilton on sex tape: I'll never be able to erase it. CNN, [Sl.], 2011. Disponível em:

<http://edition.cnn.com/2011/SHOWBIZ/05/31/piers.morgan.paris.hilton/index.html> Acesso em: 15 set. 2015.

MORELLET, Andre. Sobre a conversação: seguido de um ensaio de Jonathan Swift. São Paulo: Martins Fontes, 2002. (Coleção Breves Encontros). 
NETIQUETTE Guidelines. [Site]. 1995. Disponível em: <http://tools.ietf.org/html/rfc1855> Acesso em: 15 set. 2015.

O'CONNOR, Laurel. Celebrity Nude Photo Leak: just one more reminder that privacy does not exist online and legally, there's not much we can do about it. Digital Commons: the legal scholarship repository. San Francisco: Golden Gate University School of Law, 2014.

PASSOS, Clarissa. Por que a campanha da Always não é tão legal quanto parece. Buzzfeed, [Sl.l.], 2015. Disponível em: <http://www.buzzfeed.com/clarissapassos/a-campanha-daalways-nao-e-tao-legal-quanto-parece\#.teBm6gN6NY>. Acesso em: 15 set. 2015.

POLTASH, Nicole. Snapchat and Sexting: a snapshot of baring your bare essentials.

Richmond Journal of Law \& Technology, v. 19, n. 4, 2013. Disponível em:

<http://jolt.richmond.edu/v19i4/article14.pdf>. Acesso em: 22 nov. 2015.

PRIMO, Alex. Os blogs não são diários pessoais online: matriz para a tipificação da blogosfera. Revista FAMECOS, Porto Alegre, v. 36, p. 122-128, 2008.

QUALMAN, Erik. Socialnomics: how social media transforms the way we live and do business. Hoboken: Wiley, 2009.

RANUM, Orest. Os refúgios da intimidade. In: Ariès, Philippe; Chartier, Roger (eds.), História da vida privada: Da Renascença ao Século das Luzes. São Paulo: Companhia das Letras, 1991. (p. 211-265).

SANSEVERINI. 11 coisas que você nunca deve fazer no Facebook.Youpix, mai. 2012.

Disponível em: <http://youpix.virgula.uol.com.br/top10/11-coisas-que-voce-nunca-devefazer-no-facebook> Acesso em: 15 set. 2015.

SAUTER, Theresa. Chatroulette: bodily transgression, sex and the care of the self. Brisbane: Queensland University of Thechnology, [2011]. Disponível em: <https://www.tasa.org.au/wp-content/uploads/2011/11/Sauter-R0091-final.pdf> Acesso em: 8 jul. 2015.

SENFT, Theresa. Camgirls. Celebrity \& community in the age of social networks. New York: Peter Lang, 2008.

SHIFMAN, Limor. Memes in Digital Culture. Cambridge: MIT Press, 2014.

SIBILIA, Paula. Intimidade escancarada na rede: blogs e webcams subvertem a oposição público/privado. In: CONGRESSO BRASILEIRO DE CIÊNCIAS DA COMUNICAÇÃO, 26., Belo Horizonte, 2003. Anais... Belo Horizonte: Intercom, 2003.

SIBILIA, Paula. 0 show do eu: a intimidade como espetáculo. Rio de Janeiro: Nova Fronteira, 2008. 
Private communication on the internet: from the invention of the particular in the Middle Ages to hyper-disclosure on the net

\begin{abstract}
This paper discusses privacy in online conversations. First, we present a brief archeology of private life and a discussion on interpersonal and group interactions on digital communication services. Considering that the frontier between public and private spheres has been blurred, we present some sociability protocols that intend to guide behaviors and avoid problems with the circulation of private messages. Finally, we discuss what happens when those protocols are broken and intimate contents leak, becoming (deliberately or not) publically available.
\end{abstract}

\title{
Keywords
}

Privacy. Public. Intimacy. Online relationships. Friendship.

Recebido em 16/09/2015

Aceito em 09/12/2015 